\title{
O ensino de arte na educação de jovens e adultos: uma análise a partir da experiência em Cuiabá (MT)'
}

\author{
Gustavo Cunha de Araújo" \\ Ana Arlinda de Oliveiral"
}

\section{Resumo}

0 artigo apresenta os resultados de uma pesquisa de mestrado desenvolvida no Programa de Pós-graduação em Educação da Universidade Federal de Mato Grosso, na qual buscamos compreender como acontecem as práticas pedagógicas no ensino de arte na Educação de Jovens e Adultos (EJA) em Cuiabá, Mato Grosso. Como procedimento metodológico, o estudo fundamentou-se na pesquisa qualitativa, de caráter descritivo e interpretativo. Concebendo a docência em uma concepção construtivista, baseada na proposta triangular para o ensino da arte, ressaltando o fazer, a leitura e a contextualização durante as aulas, observou-se como uma professora agiu como mediadora na construção do conhecimento em arte. Esse conhecer é importante, pois a educação é fundamentada na construção de conhecimento e tem na atividade humana, neste caso, a arte, a sua concretização. Embora alguns jovens e adultos tenham demonstrado conceitos de arte que necessitem ser ampliados, por meio do conhecimento das diferentes manifestações artísticas, notou-se como a professora procurou desenvolver nesses educandos a concepção de que arte é uma produção humana, ou seja, objeto de conhecimento que faz parte da vida desde os primórdios da humanidade. Além disso, procurou ensinar que aprender a ler e a compreender uma obra são ações que fazem dos alunos leitores competentes para produzirem interpretações significativas do mundo à sua volta. Portanto, as concepções e práticas produzidas pelos alunos acerca da arte são importantes, pois são construções de conhecimento baseadas em suas experiências de vida.

\section{Palavras-chave}

Ensino de arte - Educação de jovens e adultos - Práticas pedagógicas - Concepções sobre a arte.

I- Dissertação de Mestrado financiada pela Coordenação de Aperfeiçoamento de Pessoal de Nível Superior - CAPES.

II- Universidade Federal de Mato Grosso, Cuiabá, MT, Brasil

Contatos: gustavocaraujo@yahoo.com.br; aarlinda_oliveira@hotmail.com 


\title{
Teaching art in youth and adult education: an analysis of an experience in Cuiabá city, Brazil
}

Gustavo Cunha de Araújol

Ana Arlinda de Oliveira'

\begin{abstract}
This article presents the results of a Master's study conducted at the Graduate Program in Education of Universidade Federal do Mato Grosso, which sought to understand how educational practices occur in the teaching of art in Youth and Adult Education in Cuiabá city, Mato Grosso state, Brazil, using qualitative, descriptive and interpretative methodology. Conceiving teaching in a constructivist perspective, based on the triangular proposal for the teaching of art, which emphasizes actual doing, reading and contextualization during the classes, we observed how the teacher acted as a mediator in the construction of the knowledge of art. Such knowledge is important as education is grounded on the construction of knowledge, which is actually achieved by human activity and, in this case, art. Although some young and adult students had concepts of art that needed to be expanded, the teacher sought, through the contact with the different artistic expressions, to lead students to develop the concept that art is a human production, that is, an object of knowledge which has been an integral part of life since the dawn of mankind. She also sought to teach that learning how to read, how to understand a work of art, makes students become competent readers who can produce meaningful interpretations of the world around them. Therefore, the concepts and practices of art produced by students are important, as they are constructions of knowledge based on their life experiences.
\end{abstract}

\section{Keywords}

Teaching art - Youth and adult education - Educational practices - Concepts of art.

I- Universidade Federal de Mato Grosso, Cuiabá, MT, Brasil

Contact: gustavocaraujo@yahoo.com.br; aarlinda_oliveira@hotmail.com 


\section{Introdução}

Este artigo apresenta os resultados de uma pesquisa de mestrado desenvolvida no Programa de Pós-graduação em Educação da Universidade Federal de Mato Grosso, na qual buscamos compreender como acontecem as práticas pedagógicas no ensino de arte em uma turma de alunos do Centro de Educação de Jovens e Adultos (CEJA) em Cuiabá, Mato Grosso, e que concepções fundamentam essas práticas desenvolvidas nas aulas de arte. Como procedimento metodológico, o estudo fundamentou-se na pesquisa qualitativa, de caráter descritivo e interpretativo. Por esse caminho, buscamos observar e retratar atentamente a perspectiva dos sujeitos, a obtenção de dados descritivos no contato direto do pesquisador com a situação estudada, o que favoreceu a compreensão do problema central do estudo.

Os instrumentos de coleta e análise de dados utilizados nesta pesquisa foram: I) entrevistas ${ }^{1}$ gravadas com alunos de EJA, que posteriormente foram transcritas; II) registro escrito das aulas de arte observadas no caderno de campo e registros visuais das práticas pedagógicas da professora e do fazer artístico dos alunos; III) análise de documentos como o Projeto Político Pedagógico (PPP) da escola pesquisada planos de aula da professora de arte, e Resoluções a respeito da legalização da EJA no Brasil e no Estado de Mato Grosso.

0 artigo está dividido em duas partes. $\mathrm{Na}$ primeira, buscamos apresentar as análises mais significativas das práticas pedagógicas desenvolvidas pela professora de arte, com o intuito de desvelar como se desenvolve o ensino e aprendizagem de arte com uma turma de Educação de Jovens e Adultos (EJA), segmento ensino médio, em Cuiabá, Mato Grosso. Em seguida, são apresentadas as análises das concepções dos alunos da EJA a respeito da arte. Nessa segunda parte, nossa intenção foi buscar

1- As entrevistas com os sujeitos desta pesquisa obedeceram aos procedimentos éticos estabelecidos para a pesquisa científica, respeitando seus anonimatos. compreender quais concepções os envolvidos na pesquisa tinham a respeito da arte e como elas fundamentavam as práticas pedagógicas desenvolvidas pela docente.

A manifestação artística acompanha a própria evolução do homem. É na escola que o jovem e o adulto irão socializar suas experiências, desenvolver novas habilidades e aprender novos conceitos e teorias que os acompanharão ao longo de suas vidas. Pelo fato de a maioria desses alunos já ter uma larga experiência de vida, terão a possibilidade de trocar experiências uns com os outros, socializando e construindo conhecimento.

\section{Práticas pedagógicas em arte na educação de jovens e adultos}

A Educação de Jovens e Adultos no Brasil vem constituindo-se, nos últimos anos, como uma importante modalidade de ensino que busca fazer frente às desigualdades sociais e à exclusão escolar. Nesse sentido, a escola tem sido um importante meio para a inclusão daqueles jovens e adultos que, por diversos e diferentes motivos, não puderam iniciar ou dar continuidade a seus estudos na educação básica.

A diversidade discente presente na EJA, composta por diferentes idades, profissões e experiências de vida, torna o seu modelo pedagógico e curricular mais flexível, para atender plenamente as necessidades de aprendizagem do jovem e do adulto. Essa flexibilidade pode ser expressa em:

[...] combinações entre ensino presencial e não presencial em uma sintonia com temas da vida cotidiana dos alunos, para que possam se tornar elementos geradores de um currículo pertinente. (BRASIL, 2000, p. 61).

Para Di Pierro (2005), é importante a Educação de Jovens e Adultos desenvolver-se junto a uma autonomia perante as mudanças socioculturais cada vez mais frequentes nos dias atuais, tendo no direito à educação 
sua ferramenta mais importante para a democratização. Nesse sentido, não apenas se busca o direito a uma educação com qualidade, mas o reconhecimento do jovem e do adulto como importantes sujeitos da educação.

A partir disso, a educação torna-se indispensável para o exercício da cidadania e para a formação cultural e senso crítico do indivíduo. Nessa reflexão, para Paiva (2007), a EJA não se torna apenas um direito, mas uma emancipação do desenvolvimento humano para a participação na sociedade enquanto cidadãos.

Por outro lado, os principais problemas relacionados à EJA como a evasão escolar, que ocasiona a não permanência do aluno na escola, não pode ser considerada problema específico na Educação de Jovens e Adultos, pois se trata de algo pertinente em toda a educação básica brasileira (CANDA, 2012). Pensamos que, para compreendermos geralmente a baixa autoestima presente nesses alunos, é necessária uma reflexão mais profunda acerca das condições sociais em que os mesmos se encontram.

Assim, entendemos que as aulas de arte podem ser espaços oportunos para que jovens e adultos trabalhem "a desinibição, a baixa autoestima, a consciência corporal e o cultivo da socialidade" (BRASIL, 2000, p. 61), pois são sujeitos que apresentam diferentes níveis de aprendizagem, os quais precisam ser observados pelo professor.

A exclusão escolar é apenas uma das formas de negação do direito do jovem e do adulto de conhecer e vivenciar a experiência artística universal, denominada por Canda (2012) analfabetismo estético, que se refere ao não contato ou acesso do indivíduo a diferentes manifestações artísticas. Assim, contribui ao afirmar:

Os espaços destinados à produção e fruição artística vêm sendo negados historicamente às classes populares. Por outro lado, consideramos que a formação para a vivência cultural plena incentiva o gosto e a valorização da obra de arte, como conjunto de conhecimentos simbólicos e culturais. (CANDA, 2012, p. 16).

Diante disso, entendemos que o espaço escolar pode oferecer possibilidades de apreciação e de produção artística ao jovem e adulto da educação, desde que o mesmo tenha contato e acesso a diferentes linguagens artísticas. Outra condição é que o professor e a escola possam oferecer ao aluno essa oportunidade de vivenciar a experiência estética, importante para o seu processo de ensino e aprendizagem e, consequentemente, para construção de conhecimento. Reflexões como essas relacionadas ao ensino de arte na Educação de Jovens e Adultos instigam-nos a pesquisá-lo no campo educacional.

Durante as aulas de arte da professora ${ }^{2}$ dessa disciplina, pudemos observar que as suas práticas pedagógicas com a turma de Educação de Jovens e Adultos eram baseadas na proposta triangular para o ensino da arte. Mostrou constantemente imagens, vídeos e biografias de artistas visuais, contextualizando temas da história da arte para a realidade dos jovens e dos adultos e levando-os para fora da sala de aula para realizar o fazer artístico. Ou seja, os alunos faziam os trabalhos de arte após a professora contextualizar o conteúdo em sala de aula ou na sala de vídeo. Utilizavam desde materiais tradicionais artísticos como pincéis, tintas e lápis até materiais como pedras, areia e plantas na produção artística.

Contextualizar, ler e fazer. Esta é a proposta para o ensino da arte, na concepção da proposta triangular, que busca efetivamente a construção do conhecimento em arte e que foi bastante enfatizada pela professora durante as aulas com a turma de EJA. Dos anos noventa até os dias atuais, essa proposta vem se mostrando como a principal tendência pedagógica presente nas escolas brasileiras. Sistematizada no final da década de 1980 e colocada em

2 - A professora é graduada em educação artística, com habilitação em música. É professora efetiva do Estado de Mato Grosso há 18 anos, sendo 15 desses dedicados à Educação de Jovens e Adultos (EJA.) 
prática no Museu de Arte Contemporânea da Universidade de São Paulo, no período entre 1987 e 1993, apresenta como objetivo central atender as reais necessidades de aprendizagem e conhecimento em arte do aluno por meio do fazer arte (criação/produção), da análise ou decodificação (leitura de imagens/apreciação) da obra de arte e contexto ou informação (história da arte/contextualização) (BARBOSA, 1988). É por isso que um dos objetivos desta pesquisa também foi compreender se as práticas desenvolvidas pela professora são baseadas na referida proposta:

A Proposta Triangular deriva de uma dupla triangulação. A primeira é de natureza epistemológica, ao designar os componentes do ensino/aprendizagem por três ações mentalmente e sensorialmente básicas, quais seja: criação (fazer artístico), leitura da obra de arte e contextualização. A segunda triangulação está na gênese da própria sistematização, originada em uma tríplice influência, na deglutição de outras três abordagens epistemológicas: as Escuelas Al Aire Libre mexicanas, o Critical Studies inglês e o movimento de apreciação estética aliado ao DBAE (Discipline Based Art Education) americano. (BARBOSA, 1998, p. 33-34).

Nesse sentido, destacamos que qualquer "conteúdo, de qualquer natureza visual e estética, pode ser explorado, interpretado e operacionalizado através da Proposta Triangular" (BARBOSA, 1998, p. 38), além de possibilitar ao professor a pesquisa. Daí justifica-se o fato da Proposta Curricular no Estado de Mato Grosso, no que toca ao ensino de arte, basear-se também nessa proposta.

0 homem sempre utilizou imagens para representar a realidade que o cerca, surgindo daí a relação entre arte e realidade. Sendo o jovem e o adulto os criadores, autores de suas obras, podemos afirmar que, a partir dos trabalhos feitos pela turma de EJA, os alunos conseguiram refletir uma nova realidade humana.
0 fazer artístico dos alunos da escola pesquisada ressaltou o processo criativo de cada um, fazendo surgir interessantes trabalhos de arte. Um exemplo é a escultura de São Benedito (figura 1), uma obra contemporânea feita a partir do tema da religiosidade, aspecto muito significativo no contexto da cuiabania - termo usado para marcar a identidade das manifestações culturais, dos modos de vida e dos valores da cidade de Cuiabá, MT. É uma obra original, efêmera como a arte contemporânea permite, mas elaborada segundo os procedimentos técnicos da Land Art ou arte da terra - movimento artístico surgido em meados do século XX nos Estados Unidos, baseado na interferência com o meio ambiente na produção da obra de arte. Esses procedimentos foram contextualizados pela professora em aulas anteriores à execução da escultura. Nesse sentido, é importante destacar que são variados os procedimentos implícitos presentes na elaboração de uma obra “e também inusitados, em especial quando se trata de obras de arte contemporânea, transpondo fronteiras entre as linguagens" (COUTINHO, 2009, p. 179).

Figura 1 - Escultura de São Benedito

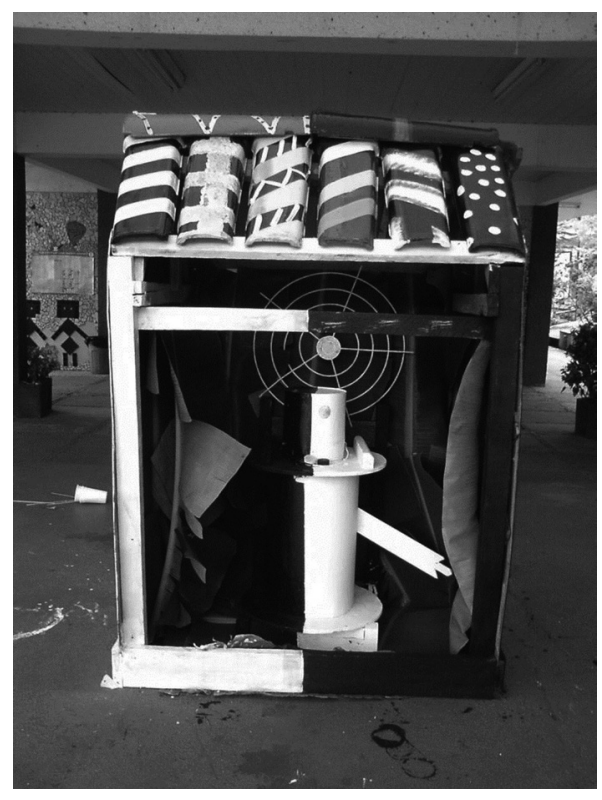

Fonte: registro dos pesquisadores. 
A partir dessas reflexões, entendemos que a obra de arte foi um instrumento de diálogo e comunicação, no qual o aluno da EJA pôde expressar suas ideias, sentimentos, emoções que, uma vez objetivadas, foram socializadas e compartilhadas.

Durante as aulas, a professora afirmou aos alunos que a arte tem várias funções, dentre elas a denunciativa, ou voltada para a conscientização do homem na natureza, para que o mesmo possa preservar o meio ambiente em que está inserido, indo ao encontro da Land Art. Disse ainda que, no dia que não existir a natureza, o homem também não existirá. Completou afirmando que os discentes deveriam ver a arte, dentre as suas várias linguagens, com cuidado, com um olhar detalhado e não despercebido.

Afirmou ainda que a arte faz parte do conhecimento dos alunos e que hoje se tem um patrimônio cultural muito rico e preservado para as pessoas verem e conhecerem a arte de outras épocas. Incentivou os alunos a conhecerem outros temas e assuntos relacionados às artes, mesmo depois que acabarem as aulas, pois, segundo ela, o conteúdo de artes muda durante $\mathrm{o}$ ano letivo escolar.

Segundo Coutinho (2009), a mediação amplia a interpretação da obra. Ou seja, quando novas informações - mídias de comunicação, por exemplo - são socializadas ao indivíduo e quando o mediador - o professor, por exemplo - propõe questões instigadoras e que podem ser significativas a esse indivíduo sobre a obra visual, contribui para a ampliação da interpretação e do conhecimento da obra.

Nesse sentido, entendemos que seria uma rica e boa oportunidade para que o jovem e o adulto da educação pudessem apreciar e participar de uma exposição de arte realizada com seus trabalhos, pois foram os autores das obras. É por isso também que pensamos não apenas em espaços como museus e centros culturais para que o aluno da EJA frequente e a eles tenha acesso. Sim, esses espaços são muito importantes. Mas, a escola também pode oferecer a esse educando a oportunidade de socialização da arte, desde que lhe possibilite espaços adequados para a realização e consequente exposição desses trabalhos, valorizando não apenas a arte enquanto área do saber e disciplina do currículo escolar, mas o próprio trabalho feito pelo jovem e adulto:

A escola, na sociedade letrada, é uma instituição voltada para o desenvolvimento do ser individual, quanto para promover o encontro daquilo que é universal no ser humano. Toda compreensão, por mínima que seja, da expressão artística é uma construção social e histórica. (ALVARES, 2012, p. 44).

Um aspecto muito importante a ser destacado na prática da professora foi o fato de ressaltar, mesmo que brevemente, obras de artistas brasileiros durante a realização dos trabalhos feitos pelos alunos. A nosso ver, isso é muito importante, pois afasta um pouco a hegemonia europeia tão presente em nossa sociedade. 0 professor de arte deve não apenas valorizar artistas internacionais, mas também dar atenção à produção artística local, regional e nacional. Trata-se de uma forma de valorizar a arte produzida no Brasil, que, aliás, é riquíssima. 0 aluno precisa ter esse contato, ampliar esse conhecimento.

Em Mato Grosso, especificamente em Cuiabá, há grandes artistas que se destacam no Estado, no país e fora dele também, como Gervane de Paula, Nilson Pimenta, Clovis Irigaray, entre outros. Esses artistas foram apresentados aos alunos pela professora, o que mostra a importância que a docente dá à contextualização da arte produzida no local onde o jovem e o adulto estão inseridos, para que possam conhecer e compreender a arte produzida em seu país.

Por outro lado, é importante ressaltar que alguns textos trabalhados pela professora com os alunos da EJA, em nossa avaliação, foram superficiais, pois trouxeram algumas 
informações incompletas ou confusas a respeito dos temas e conteúdos de arte tratados nas aulas, como a Land Art, a arte rupestre e a arte moderna brasileira, além de alguns não terem sido lidos em sala de aula. Pudemos verificar que alguns exemplos trazidos pelos textos foram pontuados pelos alunos, principalmente nas aulas práticas, como na de Land Art, o que foi um aspecto positivo.

Levar textos para trabalhar com os alunos, ainda mais o jovem e o adulto é uma forma de instigar nesses sujeitos a importância que a leitura pode ter na vida deles, mas, para isso, é preciso que o professor provoque no aluno esse gosto pela leitura, que o motive a ler. Entendemos que o hábito de leitura pode ter influência cultural e familiar, mas o aluno é o centro da aprendizagem e deve ver no professor o mediador para que possa realizar leituras visuais e textuais que sejam críticas e significativas.

Cada aula observada da professora teve uma proposta diferente. Houve momentos em que trabalhou apenas com textos impressos, porém, na maioria das aulas, foi enfatizado o fazer artístico. Houve, ainda, aulas que foram mais explicativas e outras mais questionadoras. Ou seja, não era apenas uma professora explicadora, mas questionadora também. Talvez isso explique o fato de algumas aulas não terem tanta relação com as outras. Contudo, todas deveriam ser norteadas por um ponto comum: relacionar-se com o tema Terra, que era o projeto pedagógico trabalhado pela escola no trimestre. Por isso, entendemos ser importante a professora questionar os alunos acerca do universo da arte, para que os mesmos possam ser motivados:

[...] a questionar e a encontrar respostas para as questões a respeito das obras artísticas de nosso convívio, seus autores, seus espectadores, situados no tempo/ espaço local e internacional, o que poderá ajudar na ampliação e diversificação do nosso repertório prático e teórico relativo às dimensões do processo artístico.
Durante o desenrolar desses exercícios de análise, comparação e contraposição entre obras de arte brasileira de nossa região e as de outras regiões e países, mobilizamos transformações em nossos saberes alcançando novos "patamares" de entendimento no campo da arte e da sua história. (FERRAZ; FUSARI, 2010, p. 141).

De acordo com o seu planejamento, que era trimestral, foi possível notar que a professora não contemplou todo o conteúdo pretendido por ela no período. Pensamos que isso ocorreu devido ao fato da disciplina de arte ter carga horária reduzida no currículo escolar, o que pode prejudicar os alunos, pois perdem a oportunidade de aprender e ampliar seus conhecimentos. Nesse sentido, é importante dar mais atenção a essa disciplina na escola, pois, além de ser uma área do saber, promove a construção de conhecimento.

É possível o jovem e o adulto aprenderem a apreciar uma obra de arte. 0 conhecimento artístico é um aprendizado que se inicia por meio da observação de uma obra. Depois, os interessados precisam dar continuidade a esse conhecimento buscando o contexto da obra, do autor etc. Sabemos que o conhecimento em arte amplia a compreensão do mundo e melhora a capacidade de expressão. Isso aconteceu quando os alunos criaram suas obras originais, como a escultura de São Benedito, bastante contemporânea (figura 1) e um bom exemplo de como o contexto sociocultural da cidade foi trabalhado no currículo escolar.

Quanto aos trabalhos feitos pelos alunos de EJA durante as aulas de arte, podemos afirmar que basicamente todos foram desenhos, o que mostra o quanto essa linguagem ainda é predominante na sociedade e na cultura visual. Mesmo sendo desenhos de observação, de imaginação ou de memória, as pessoas ainda representam bastante a realidade por meio dessa linguagem.

Essa observação conduz-nos a dizer que o desenho, enquanto linguagem presente 
historicamente na cultura visual, é a base para diversas produções e expressões visuais contemporâneas - pintura, gravura, histórias em quadrinhos, grafite etc. Daí sua presença ser tão fortemente marcada nos trabalhos realizados pela turma da EJA que acompanhamos.

A saída com os alunos da EJA da sala de aula para realizar a maioria dos trabalhos orientados pela professora possibilitou intensificar as interações sociais entre todos, além de terem a oportunidade de pesquisarem e utilizarem diferentes objetos para a produção artística, como pedras, areia, terra, plantas entre outros, como pode ser visto nas figuras 2 e 3 :

Figura 2 - Trabalho sobre Land Art 1

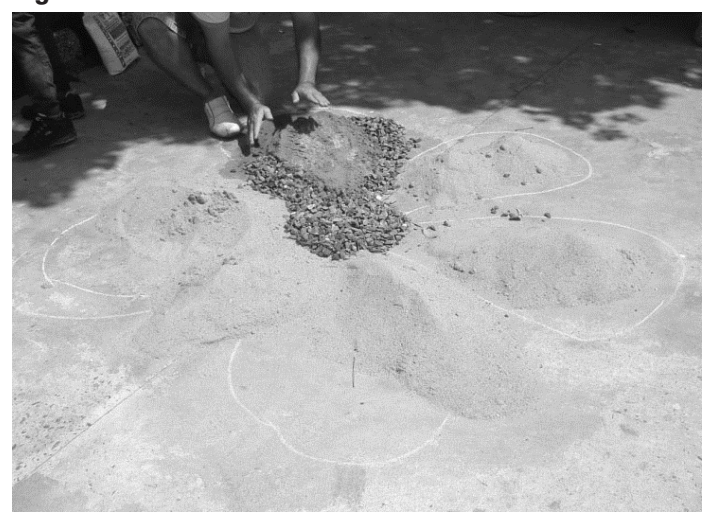

Fonte: registro dos pesquisadores.

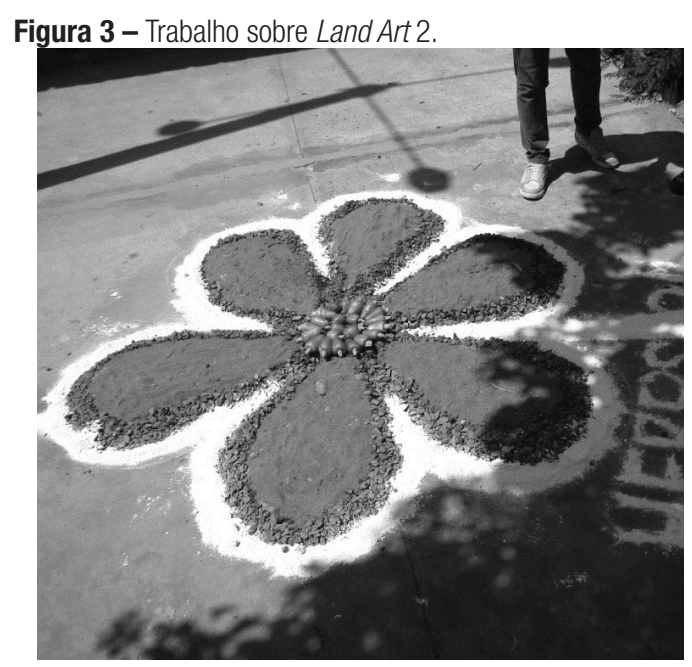

Fonte: registro dos pesquisadores.
Observamos também que, pelo fato de trazerem uma bagagem de vida significativa, os jovens e adultos conseguiram ser mais participativos nas aulas. A professora buscou, por meio de alguns trabalhos desenvolvidos em sala de aula e fora dela, estabelecer relações com a realidade do aluno, centralizando a educação em suas histórias de vida, visando a contribuir para o seu processo de ensino e aprendizagem.

Para ampliar a compreensão das práticas pedagógicas desenvolvidas pela professora e desvelar que concepções os alunos da EJA tinham a respeito da arte, abordaremos, em seguida, as análises significativas realizadas a partir das entrevista feitas com os sujeitos desta pesquisa, que foram gravadas e transcritas.

\section{O que pensam alunos da Educação de Jovens e Adultos acerca da arte}

A arte na educação tem papel importante ao proporcionar aos jovens e adultos novas experiências, tornando-os indivíduos preparados para perceberem melhor o meio social em que vivem, bem como saber compreendê-lo e interagir com ele, buscando um conhecimento ampliado da arte, em suas diferentes linguagens.

Enquanto criação essencialmente humana, a arte é produzida em determinada época, contexto, cultura e sociedade, é detentora de valores, conceitos, emoções, significados e expressão da realidade que a cerca. Sendo assim:

[...] estimula a inteligência e contribui para a formação integral do indivíduo, sem ter o foco na formação artística em si, por essa razão pode-se considerar que a arte se coloca como um trabalho educativo importante para a dimensão humana. (QUADROS, 2011, p. 55).

As entrevistas realizadas com esses sujeitos possibilitaram constatar, dentre outras concepções, a arte entendida como conhecimento humano e como expressão de sentimentos: 
É um aprendizado... Aprendizado... (I7)

Expressão. Forma de se expressar. (R3)

Conhecimento... Conhecimento de tudo, geral. (S2)

Arte é um meio de se expressar. (T4)

Pra mim, arte é alegria, é o jeito de expressar o sentimento que a gente tá sentindo naquele momento, às vezes momento de tristeza, às vezes de alegria, é a expressão da alegria. (09)

Arte tenta transmitir pra gente alegria... Eu acho que é muito importante na vida da gente, no dia a dia. (R6)

Arte é se expressar... Qualquer forma, desenhando... (M1)

Nessas falas, percebemos que a maioria dos alunos compreende a arte como forma de expressar seus sentimentos, sendo recorrente o termo alegria em seus depoimentos, mas também como forma de conhecimento, ao ressaltarem termos como expressão, conhecimento e aprendizagem.

A arte desperta diferentes sensibilidades. Pode despertar alegria, tristeza, ou mesmo servir de meio e expressão para denunciar ou criticar algum acontecimento social ou político ocorrido na sociedade. No entanto, é importante destacar que não se deve apenas conceber a arte como expressão do sensível, assim como esclarece Barbosa (2008), pois dessa forma o conhecimento em arte não será totalmente explorado. Ao contrário, além de expressar o sensível, a arte deve contribuir plenamente para o desenvolvimento cultural desses estudantes, no processo de ensino e aprendizagem.

Portanto, a "arte é vista como linguagem, expressão, construção, conhecimento" (FERRAZ; SIQUEIRA, 1987) e como sentimento (READ, 1987). Essas concepções estão presentes nas falas dos alunos da EJA. Nessa reflexão, a arte favoreceu o desenvolvimento da criatividade, da imaginação e do senso crítico desses importantes sujeitos da educação.

Descobrir que conhecimento em arte o aluno tem, conhecimento esse que diz respeito às linguagens e vivências artísticas, também se mostra relevante para um bom desempenho do professor de arte, e para desvelar como esse conhecimento vem sendo construído nas aulas de arte. É necessário também organizar aulas que possam abordar atividades que envolvam o fazer artístico e a análise das produções em arte (FERRAZ; FUSARI, 2010).

Ao serem perguntados a respeito de que tipo de conhecimento em arte aprenderam na escola, boa parte dos alunos ressaltou as linguagens com as quais tiveram contato durante sua vida escolar, com destaque para o desenho e a pintura:

Aprendi a pintar, aprendi a misturar cores, que é bem legal também, misturar as cores que eu não sabia antes... (C3)

Muitas coisas... Eu aprendi muito a desenhar, a pintar. (E1)

É desenho... (J6)

Principalmente a pintura. A pintura foi pra mim a mais interessante. É um conhecimento a mais que a gente adquiriu. Pra falar a verdade, você conhece a arte pelas cores, pelas cores primárias e depois você... vai desenhando, se destacando mais... (J2)

Artesanato, pintar. (K8)

Aprendi que não é só ficar ali pintando... Até mesmo um rabisco é uma obra de arte, mesmo a gente passando um pincel ali é uma obra de arte. (V5)

As declarações mostraram um aspecto interessante: mais da metade entende que o 
conhecimento em arte aprendido na escola está relacionado a algum tipo de linguagem artística com que tiveram contato na escola, como é o caso do desenho e da pintura, sendo esta última a linguagem que a professora mais trabalhou nas aulas de arte com esses alunos, apesar de sua formação acadêmica ser em música.

Nesse sentido, é importante destacar que o conhecimento em arte não deve estar voltado ao aprendizado das linguagens artísticas sem estar relacionado ao fazer, à experimentação e à informação da história da arte, ou seja:

[...] quando falo de conhecer arte, falo de um conhecimento que nas Artes Visuais se organiza inter-relacionando o fazer artístico, a apreciação da arte e a história da arte. Nenhuma das três áreas sozinhas corresponde à epistemologia da arte. (BARBOSA, 2012, p. 33).

Portanto, é necessário que esse conhecimento esteja relacionado ao aprendizado das manifestações artísticas baseados nas dimensões da leitura, do fazer e da contextualização. Ao construir conhecimento em arte, o qual também envolve compreender os estilos artísticos, os artistas, os materiais e procedimentos técnicos utilizados ao longo da história da arte, o aluno da EJA pode aprender a perceber, refletir, analisar e distinguir o mundo à sua volta, ampliando a sua capacidade de interpretação da realidade.

As diferentes representações da arte no meio social suscitam e influenciam a concepção que os jovens e adultos têm de arte. Sabemos que os alunos vivem em uma sociedade imagética. A imagem, de diferentes linguagens, invade suas casas, trabalho, enfim, está presente em praticamente todos os lugares. Pelo fato de terem um grande poder de representação, influenciam os conceitos de arte formados por jovens e adultos. Quando chegam à escola, trazem esses conceitos pré-formulados, de acordo com suas experiências com a cultura visual.

Nos dias atuais, o jovem e o adulto deparam-se constantemente com diversas formas de linguagens, como a verbal, a imagética (o desenho, por exemplo) entre tantas outras, importantes para a comunicação humana, que vão ser exemplos de como se pode transmitir ideias, conceitos e informações uns aos outros.

Nesse sentido, a linguagem está diretamente ligada ao ato de comunicar-se com o outro, transmitindo informações e experiências que podem ser individuais ou coletivas. A partir disso, a arte assume importante papel na sociedade ao ser a linguagem que mais expressa e transmite informações e sentidos às pessoas, devido à diversidade de linguagens $\mathrm{e}$ procedimentos artísticos existentes em seu campo de conhecimento.

Assim, perguntamos aos alunos de quais linguagens artísticas mais gostavam:

A música. Bastante! (H7)

Música. (J6)

Eu gosto de música! (L9)

Música, dança, cinema... (M1)

Falar de dança, eu nasci dançando... Meu irmão... que é meu pai de criação, que... Meu pai foi embora muito cedo, então, ele assumiu, 10 anos mais velho que eu, ele assumiu eu como filho. Então, ele era um dançarino nato das músicas regionais nossas, então... A gente viveu música dentro de casa, então a gente gosta muita de dançar. Hoje eu tô aprendendo, porque eu nunca tive aula de arte assim quando moleque, e hoje, voltando na sala de aula, eu to pegando a arte, estudando arte moderna, tal, cubismo, expressionismo... Então, são coisas novas pra mim, mas que eu tô adorando também, mas que o forte é a dança mesmo. (09).

A minha música e cinema... Não vivo sem cinema! (R3)

Música... (R6) 
Música, mas a professora não trabalha. Teatro mesmo eu gosto, agora apresentar... (V5)

As falas dos alunos deixaram-nos surpresos, pois, embora a música esteja presente na vida das pessoas não apenas como uma manifestação artística e cultural, mas também como lazer, quase a totalidade dos jovens e adultos respondeu que gostava de música, uma das linguagens que a professora não trabalhou durante as aulas de arte observadas, ainda que sua formação seja nessa habilitação. Também não constatamos no planejamento da professora nenhum tema relacionado à música. Portanto, podemos afirmar que dificilmente trabalhariam com essa linguagem durante o período em que teriam aulas com ela, mesmo os alunos tendo demonstrado interesse por essa linguagem, pois a carga horária da disciplina na escola era bem reduzida em comparação com as demais disciplinas do currículo escolar.

A ausência dessa linguagem foi reconhecida pela aluna V5, que declarou que a professora não trabalhou com música durante as aulas de arte, o que mostrou o quanto os alunos estão atentos ao trabalho pedagógico da professora em sala.

É sabido que existem inúmeras linguagens da arte que se impõem como importantes para que a escola as priorize. Mas é importante que isso seja feito de forma aprofundada e em suas especificidades (IAVELBERG, 2003), mesmo tendo conhecimento, a partir das falas dos alunos e das observações in loco realizadas no campo da pesquisa, de que os alunos tiveram contato basicamente com desenho e pintura. Ao serem perguntados a respeito do que gostavam de fazer nas aulas de arte, os jovens e adultos, assim descreveram:

Eu gosto mais de pintar... Nas aulas dela, eu acho bem legal. (C3)

Assistir vídeo e fazer trabalhos depois do vídeo é muito bom. (E1)
Adoro assistir os vídeos. (J2)

No caso, pintar mesmo! (J9)

Pintar é muito legal! (K8)

Eu gosto de pintar! (L9)

Quando ela passa vídeo. (M1)

Pintar. (S2)

De acordo com seus relatos, os alunos gostam mais de pintar, talvez justamente pelo fato da pintura ser a linguagem mais utilizada pela professora durante as aulas. Para alguns alunos, como é o caso de E1 e M1, eles preferem assistir a vídeos, que eram os momentos em que a professora contextualizava o tema trabalhado na aula, mostrando aos alunos imagens e informações acerca da história da arte.

Em seguida, perguntamos aos jovens e adultos a respeito do que não gostavam de fazer nas aulas de arte. As respostas foram as seguintes:

De desenhar. (E1)

Ah... Desenhar. (J6)

Não gosto muito de escrever, não. Aula de artes é alguma coisa de artes. (L5)

Copiar matéria. Copiar eu não gosto. (R3)

Escrever. (R6)

Da parte do desenho mesmo. (S2)

Desenhar mesmo. (T4)

Mais da metade dos alunos disse não gostar de desenhar e escrever. Entendem também que, por ser aula de arte, não precisam ter o compromisso de escrever, mas sim de ter aula prática. Acontece que, por ser um problema histórico, em que arte 
no currículo escolar abordava praticamente aulas práticas, os alunos nos dias de hoje estranham quando as aulas assumem outros códigos como a escrita, por exemplo. É necessário, então, que o professor saiba lidar com essa situação, ao propor aulas dinâmicas, criativas e interessantes, para que o aluno não continue a pensar que aula de arte é só prática.

Com relação ao fato de desenharem, percebemos em algumas aulas que pelo fato de terem alegado à professora que, não sabiam desenhar, evitavam praticar tal atividade, realizando-a apenas como lazer fora da escola, como pôde ser constatado em suas falas. É comum esse tipo de reação do aluno, principalmente ao lidar com aulas práticas, pois exigem habilidades para desenvolver determinadas atividades. Contudo, para a arte-educação, o que importa não é se o aluno sabe ou não desenhar, se sabe ou não realizar determinado trabalho artístico, mas se ele consegue aprender e desenvolver a sua formação cognitiva, estética e cultural.

Mesmo aqueles alunos que falaram que não desenham nada são capazes de aprender a olhar uma obra de arte, aprender a levantar questionamentos a respeito da obra, como por exemplo: como o artista fez a obra? De que época é? Basta iniciar esse aprendizado, dar o primeiro passo. É preciso possibilitar ao jovem e ao adulto o aprendizado e conhecimento da arte.

É possivel ensinar a gostar de aprender arte com a própria arte (IAVELBERG, 2003). Com isso, promovem-se condições melhores de vida humana no meio natural e social. Por isso, é preciso que o jovem e adulto tenham contato com a arte para ter a oportunidade de fazer experimentações artísticas, que possam aprender e conhecer a arte pela prática e leitura, e não apenas observando. Mas, para isso, é necessário haver espaços adequados para o desenvolvimento do fazer artístico.

A escola deve não apenas proporcionar ao jovem e ao adulto a construção do conhecimento em arte, mas também possibilitar a ampliação desse saber, ao visitarem museus de arte, exposições de artistas, manifestações culturais diversas, dentre tantas outras. Nesse sentido, foi perguntado aos alunos se participavam de eventos culturais e artísticos:

Vou a cinema. (E1)

Frequento. Dança... teatro... cinema... shows com certeza! (H1)

Só show. (I7)

Eu vou pra levar meus filhos... Vou ao cinema com eles. (J2)

Sim. Com frequência... Shows, bastante. (J9)

Vou... Sempre que tem eu vou ao SESC Porto, que tem a arte lá, a dança, que faz parte da arte, a música, que faz parte da arte... teatro... Eu tô sempre no teatro, no cineteatro. (J9)

Com certeza, eu já fui a várias peças de teatro, já frequentei o teatro da UFMT, o cineteatro Cuiabá quando inaugurou. (09)

Sim, frequento. Sou sócio aqui do Chorinho, aqui do Clube do Choro, frequento o Chorinho semanalmente, toco lá também. Toco violão, percussão... (R3)

0 cinema, sim... Gosto muito de ouvir música. (R6)

Sim. Tudo que tem no SENAI, nos eventos Pantanal, sempre que tem algumas exposições expostas no shopping. (S2)

Vou ao cinema com meus colegas, meus amigos. (T4)

Cheguei a ir a shows... Teatro gosto também. (V5). 
A maioria dos alunos frequentava eventos culturais e artísticos, especialmente shows. Contudo, chamou-nos bastante a atenção o fato de ninguém ressaltar lugares como museus ou exposições de arte.

Arte é teoria. Arte é prática. Arte é um saber estético que produz conhecimento. Portanto, o saber artístico possibilita experiências cognitivas ao longo da vida (QUADROS, 2013). Com relação ao jovem e ao adulto, essas experiências são parte singular de suas vivências acumuladas ao longo de suas vidas. Assim, é pelo fato da arte estar presente de diferentes formas na sociedade que se mostrou relevante conhecer e entender de que modo ela interferiu e se manifestou nas vidas dos jovens e adultos durante as aulas de arte.

\section{Considerações finais}

Concebendo sua docência em uma concepção construtivista, baseada na proposta triangular para o ensino da arte, a professora agiu como mediadora na construção do conhecimento em arte pelo aluno jovem e adulto. Esse conhecer é importante, pois a educação é fundamentada na produção de conhecimento e tem na atividade humana, neste caso, a arte, a sua concretização.

0 fazer do aluno da EJA é muito importante, para que possa construir e ampliar o conhecimento em arte que vai desenvolvendo aos poucos, a partir do contato com a manifestação artística, para a sua formação estética e cultural. Mas, para isso, é preciso a mediação do professor que saiba organizar, elaborar, analisar, apresentar e discutir os diferentes procedimentos artísticos trabalhados em sala de aula, pois o principal eixo de ensino e aprendizagem nesse contexto é o aluno; portanto, esse deve ser o foco.

Embora alguns jovens e adultos tenham demonstrado conceitos de arte que necessitem ser ampliados por meio do conhecimento das diferentes manifestações artísticas, a pesquisa percebeu que a professora procurou desenvolver nesses alunos a concepção de que arte é uma produção humana, portanto, objeto de conhecimento que faz parte da vida do ser humano desde os primórdios. Além disso, procurou levá-los a aprender a ler a obra por meio do fazer, buscando formar leitores competentes para compreenderem os diferentes textos visuais presentes em seu meio social, produzindo interpretações significativas do mundo à sua volta.

As concepções produzidas pelos alunos a respeito da arte são importantes, pois são construções de conhecimento baseadas em suas experiências de vida. Porém, entendemos que uma das formas do jovem e do adulto ampliarem esse conhecimento e, consequentemente, a sua experiência estética, é frequentar museus, centros culturais e similares, para que tenham um contato pleno com a arte em sua forma pura. Mas, para isso, é preciso eliminar a distância existente entre esse tipo de arte designado na sociedade como elitista e o jovem e o adulto. Todos merecem ter acesso e contato com a arte universal, não apenas uma minoria.

A disciplina de arte deve proporcionar aos alunos da Educação de Jovens e Adultos essas experiências, tornando-os indivíduos preparados para compreenderem o meio social em que vivem e interagirem socialmente, buscando conhecer novas e diferentes linguagens e culturas. É preciso que tenham contato com as diferentes manifestações artísticas e que possam fazer uso delas para diferentes fins.

Constatamos que os alunos conseguiram produzir trabalhos de arte significativos e bastante contemporâneos, o que contribuiu para que pudessem conhecer mais um pouco do universo artístico - bastante desconhecido para a maioria deles - e também para que ampliassem sua experiência estética, além de se tornarem mais participativos durante as aulas.

0 jovem e o adulto constroem conhecimento por meio do que fazem. Têm no professor o principal mediador para produzir esse conhecimento e mobilizar no aluno o 
desejo de aprender. 0 professor é um formador, responsável por esse processo de formação da aprendizagem no aluno. Assim, entendemos que a professora buscou mediar a produção de conhecimento em arte no jovem e no adulto, tendo como parâmetro a proposta triangular para o ensino de arte. A linguagem utilizada pela professora em suas aulas foi o desenho e a pintura, o que reforça a predominância das artes visuais nas aulas de arte na educação básica brasileira.

Espaços culturais e artísticos como os museus de arte podem possibilitar ao aluno da EJA elevar ainda mais esse conhecimento artístico. Mas entendemos que esse conhecimento também pode ser produzido na escola. Daí a importância de o professor mediar adequadamente esse processo, ao oferecer possibilidades concretas para que o jovem e o adulto possam aprender e apreciar a arte. Por meio desse saber, é possível sobre refletir e questionar os padrões estéticos presentes na localidade em que vivem.

A arte é um conhecimento interdisciplinar. Além de proporcionar conhecimento para todas as áreas, ela contribui e traz significado para o ensino e aprendizagem na educação escolar. A arte é produção essencialmente humana e, portanto, é importante na escola.

\section{Referências}

ALVARES, Sônia Carbonell. Educação estética na EJA: a beleza de ensinar e aprender com jovens e adultos. São Paulo: Cortez, 2012.

BARBOSA, Ana Mae. A imagem no ensino da arte: anos 1980 e novos tempos. 8. ed. São Paulo: Perspectiva, 2012.

BARBOSA, Ana Mae. Inquietações e mudanças no ensino da arte. 5. ed. São Paulo: Cortez, 2008.

BARBOSA, Ana Mae. Tópicos utópicos. Belo Horizonte: C/Arte, 1998.

BRASIL. Ministério da Educação. Parecer CNE/CEB n. ${ }^{\circ} 11$ de maio de 2000. Diretrizes Curriculares Nacionais para a Educação de Jovens e Adultos. Brasília: MEC, 2000. Disponível em: <http://portal.mec.gov.br/cne/arquivos/pdf/pceb011_00.pdf>. Acesso em: 26 jan. 2015.

CANDA, Cilene Nascimento. Conscientização e ludicidade na educação de jovens e adultos: revendo caminhos teóricometodológicos. Educação Popular, Uberlândia, v. 11, n. 1, p. 10-24, jan./jun. 2012.

COUTINHO, Rejane Galvão. Estratégias de mediação e a abordagem triangular. In: BARBOSA, Ana Mae (Org.). Arte/educação contemporânea: consonâncias internacionais. 3. ed. São Paulo: Cortez, 2009. p. 171-185.

DI PIERRO, Maria Clara. Construção coletiva: as contribuições à educação de jovens e adultos. In: Políticas públicas de educação de jovens e adultos: trajetórias. Um balanço da evolução recente da educação de jovens e adultos no Brasil. Brasília: MEC/ UNESC0, 2005. p. 17-59.

FERRAZ, Maria Heloísa Corrêa de Toledo; FUSARI, Maria Rezende e. Arte na educação escolar. 4. ed. São Paulo: Cortez, 2010.

FERRAZ, Maria Heloísa Corrêa de Toledo; SIQUEIRA, Idméa Semeghini Próspero. Arte-educação: vivência, experienciação ou livro didático? São Paulo: Loyola, 1987.

IAVELBERG, Rosa. Para gostar de aprender arte: sala de aula e formação de professores. Porto Alegre: Artmed, 2003.

PAIVA, Jane. Educação de jovens e adultos: movimentos pela consolidação de direitos. Reveja: Revista de Educação de Jovens e Adultos, São Paulo, v. 1, p. 68-84, ago. 2007.

QUADROS, Imara Pizzato. Palavras científicas sonhantes em território úmido feito a mão: a arte popular da canoa pantaneira. 364 f. Tese (Doutorado em Educação) - Universidade Federal de Mato Grosso, Cuiabá, 2013. 
QUADROS, Imara Pizzato. Arte popular: trilheira para a arte/educação/ambiental. In: SAT0, Michèle (Org.). Eco-ar-te para reencantamento do mundo. São Carlos: Rima/Fapemat, 2011. p. 52-61.

READ, Herbert. 0 sentido da arte. 6. ed. São Paulo: Ibrasa: Instituição Brasileira de Difusão Cultural, 1987.

Submetido em: 13.03.2014

Aprovado em: 12.08.2014

Gustavo Cunha de Araújo é mestre em educação pela Universidade Federal de Mato Grosso e graduado em artes visuais (educação artística com habilitação em artes plásticas) pela Universidade Federal de Uberlândia.

Ana Arlinda de Oliveira é doutora em educação pela Universidade Estadual Paulista Júlio de Mesquita Filho, com pós-doutorado em educação pela Universidade Federal de Minas Gerais. É professora associada do Instituto de Educação e do Programa de Pós-graduação em Educação da Universidade Federal de Mato Grosso. 